\title{
Deformation Characteristics of Mono Strand Anchor Head
}

\author{
Sung Tae Kim, Jeong-Rae Cho, Keunhee Cho, Sung Yong Park, Young-Hwan Park \\ Structural Engineering Research Division, Korea Institute of Civil Engineering and Building Technology, \\ Goyang, Korea \\ Email: esper009@kict.re.kr, chojr@kict.re.kr, kcho@kict.re.kr, sypark@kict.re.kr, yhpark@kict.re.kr
}

Received 1 September 2014; revised 28 September 2014; accepted 12 October 2014

Copyright $@ 2014$ by authors and Scientific Research Publishing Inc.

This work is licensed under the Creative Commons Attribution International License (CC BY).

http://creativecommons.org/licenses/by/4.0/

(c) (i) Open Access

\section{Abstract}

This paper investigates experimentally the deformation characteristics of the mono strand anchor head used in prestressed concrete bridge. Since the strains measurable in the anchor head are the axial and hoop strains, the deformation characteristics of the anchor head are examined by measuring these strains at various positions and according to the jacking force exerted on the prestressing strand. Moreover, the possibility to estimate the jacking force acting in the tendon based upon the measured strains and the corresponding error are evaluated.

\section{Keywords}

Prestressed Concrete Bridge, Anchor Head, Mono Strand System, Deformation Characteristics

\section{Introduction}

Even if diverse types of bridge were developed and applied, the most preferred bridge remains the concrete bridge among which the prestressed concrete bridge represents the majority. The prestressed concrete structure makes use of tendons to supplement compressive force so as to enhance significantly the performance of the concrete structure. This combination constituted a huge progress by enabling to achieve high quality and long span structures that could not be realized by steel reinforced concrete structures.

Prestressed concrete structures can be subdivided into pre-tensioning systems and post-tensioning systems. In both systems, the strands are individually gripped in an anchor head unit including a wedge and transmit their prestressing force by means of an anchor plate. When the strand is jacked, the anchor head unit exhibits extremely complicated behavioral characteristics due to the combined effects of the anchor head-wedge contact, the wedge-strand contact, local yielding and the initial position and eccentricity of the wedge, etc.

Bastien et al. [1], Noh et al. [2], and Seo et al. [3] among others conducted research on the behavior of the 
anchor head unit using conventional steel strand for its design. Through the numerical analysis of the deformation of mono strand anchor head, Park et al. [4] verified that the deformation characteristics of the anchor head is very sensitive the initial position of the wedge. Besides, Al-Mayah and his coworkers [5]-[11], Bennitz [12], and Sayed-Ahmed et al. [13] published recently their research results on the optimal anchor head system for CFRP strand.

This paper intends to investigate experimentally the deformation characteristics of the mono strand anchor head used in prestressed concrete bridge. Since the strains measurable in the anchor head are the axial and hoop strains, the deformation characteristics of the anchor head are examined through tests measuring these strains at various positions and according to the jacking force exerted on the prestressing strand. Moreover, the possibility to estimate the jacking force acting in the tendon based upon the measured strains and the corresponding error are evaluated.

\section{Test Setup}

The testing apparatus depicted in Figure 1 is used for the experiment of the mono tendon anchor head in this study. The anchor head unit for mono tendon of KTA is adopted. The testing apparatus is conceived to exert a tensioning force on the steel strand by means of a hydraulic jack. The so-applied load is measured using a load cell. The anchorages on both sides of the apparatus present identical test conditions corresponding to the conditions of the dead anchor in actual sites. Test is executed without preset load until failure of the steel strand. The deformation of the anchor head is measured by means of 16 and 8 axial and hoop strain gages bonded respectively on the left-hand and right-hand extremities as shown in Figure 1. The hoop strain gages are disposed at positions located at $5 \mathrm{~mm}, 15 \mathrm{~mm}$ and, $25 \mathrm{~mm}$ from the outer end of the anchor head. Since different behaviors are expected at the center and end of the wedge, the hoop strain gages are distributed regularly along the circumference. Also, three displacement gages are installed as shown in the figure. Figure 2 shows a view of the test, which is performed on 2 specimens with identical conditions.

\section{Test Results and Discussion}

Figure 3 plots the load-displacement curves measured in the tests. Both specimens experienced yield of the steel

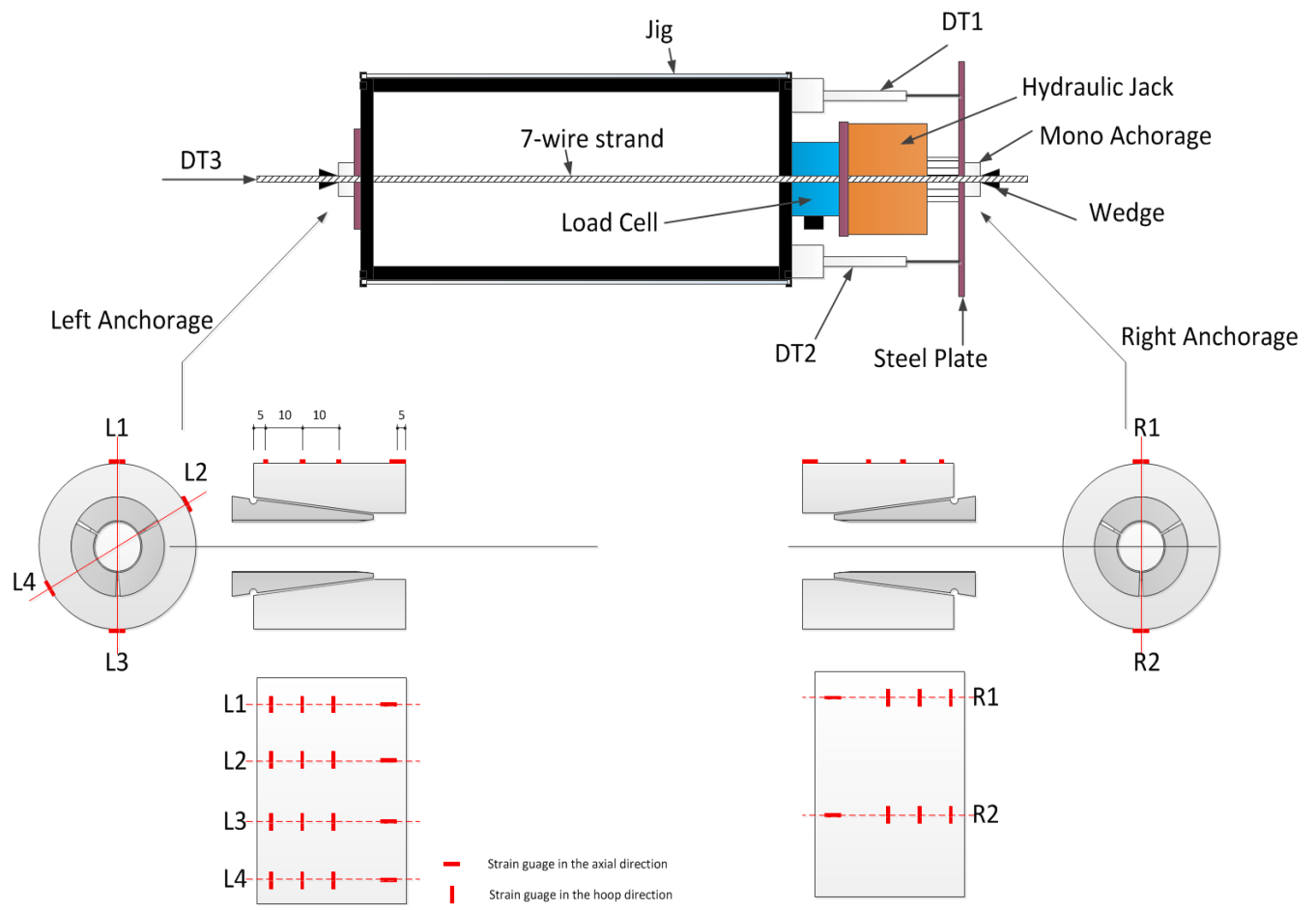

Figure 1. Test setup for mono tendon anchorage. 


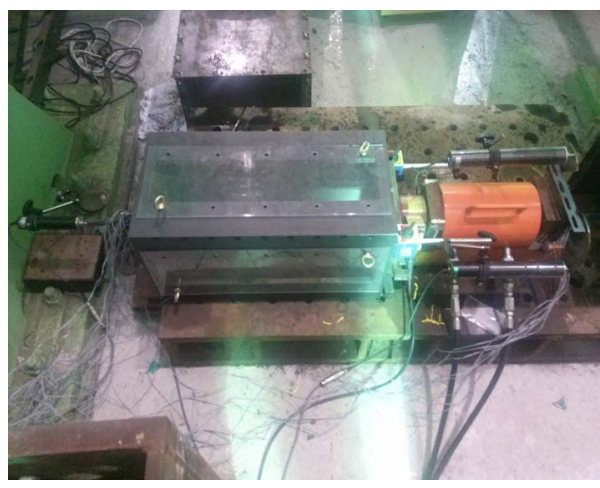

Figure 2. View of test.

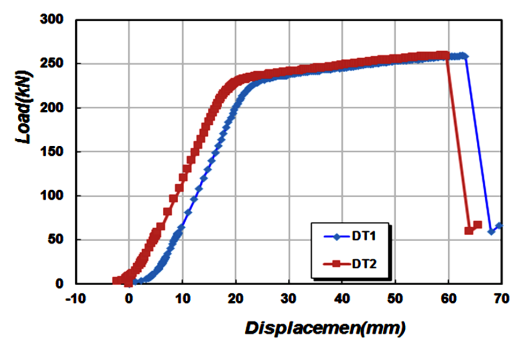

(a)

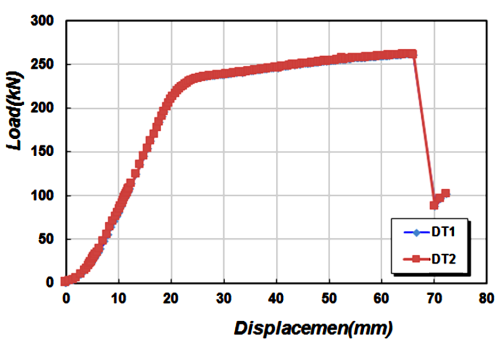

(b)

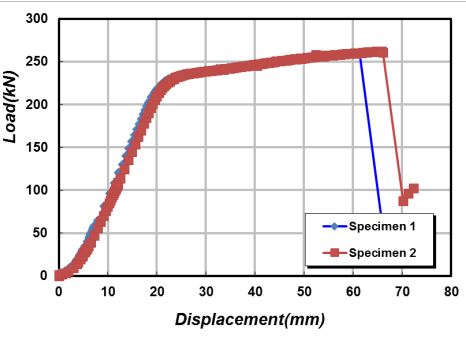

(c)

Figure 3. Load-displacement curves. (a) Load-displacement curves of specimen 1; (b) Load-displacement curves of specimen 2; (c) Load-average displacement curves.

strand around $230 \mathrm{kN}$ followed by the final breakage of the strand near $260 \mathrm{kN}$. In Figure 3(a) and Figure 3(b), it can be observed that partial eccentric loading occurred in specimen 1 in view of the different values measured by the displacement gages DT1 and DT2 whereas eccentric loading did practically not occur in specimen 2. In Figure 3(b), it appears that both specimens develop quasi-identical load-displacement curves when considering the load-displacement curves with the average of the values measured by DT1 and DT2. Figure 4 plots the slip measured by DT3 with respect to the load. The slips in both specimens show similar increasing trends but with large discrepancy in their values caused by the initial position of the wedge. Figure 5 illustrates the failure pattern of the strand that occurred near the right-hand side anchorage of specimen 1. Figure 6 depicts the disentanglement of the wires due to the impact load generated by breakage. Note that specimen 2 also exhibited identical failure pattern.

Figure 7 plots the axial strains measured in the test. In Figure 7(a) and Figure 7(b), the values of the strain show large fluctuation at identical loads with respect to the position of the strain gage in specimen 1 as well as in specimen 2. The same fluctuation can also be observed in Figure 7(c) for the mean of the axial strains at identical positions in the loaded end. Theoretically, the axial strain shall exhibit identical response at the measuring positions according to the load transfer mechanism to the tendon, wedge and, anchor head. Such large fluctuation can be explained by the relatively short length through which the load is transferred and also by the slight eccentricity of the load.

Figures 8-10 plot the hoop strains measured at distances of $5 \mathrm{~mm}, 15 \mathrm{~mm}$ and, $25 \mathrm{~mm}$ from the outer end of the anchor head. The strains at each individual spot are indicated together with the mean values at each spot. It can be observed that large variations in the hoop strain occur according to the measuring spot even of measurement is done at identical distance from the outer end of the anchor head. Especially, smaller strains were measured at wedge-wedge contact positions and, in some cases, negative strains were even observed. This can be explained by the fact that the wedge-wedge contact is a zone with small stiffness, which makes the wedges slide inwards during jacking and results in smaller strain. Similarly to the axial strain, the strain at the center of the wedge appears to have relatively smaller fluctuation. However, the averages of the strains measured at identical positions from the loaded end of the anchor head describe nonlinear curves but exhibit relative stability with smaller fluctuation. 


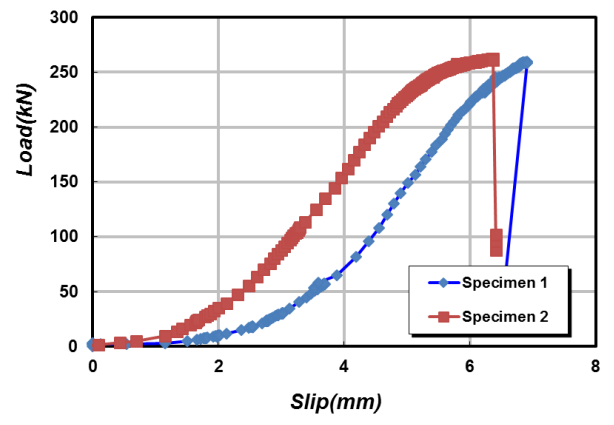

Figure 4. Load-slip curves.

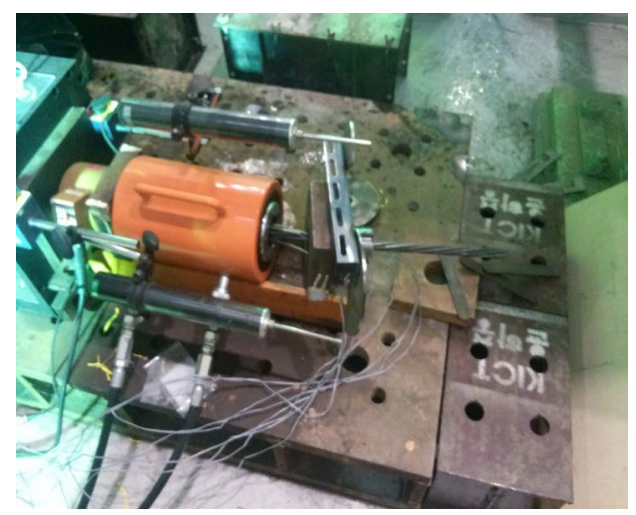

Figure 5. Failure of right-hand side anchor.

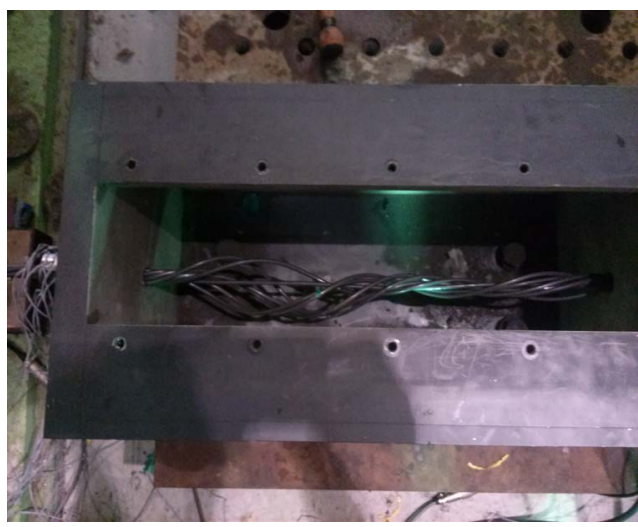

Figure 6. Disentanglement of wires cause by post-failure impact.

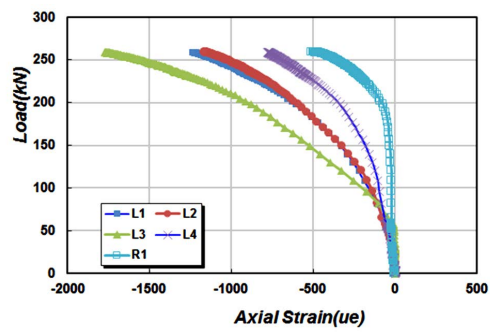

(a)

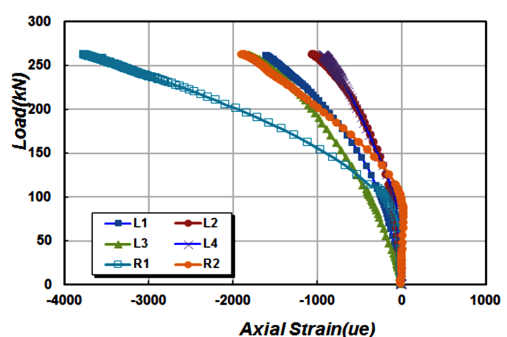

(b)

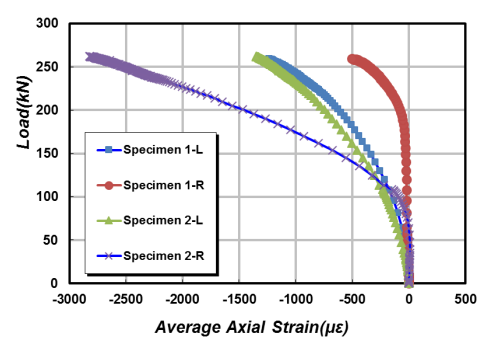

(c)

Figure 7. Load-axial strain curves. (a) Load-axial strain curves of specimen 1; (b) Load-axial strain curves of specimen 2; (c) Load-average axial strain curves. 


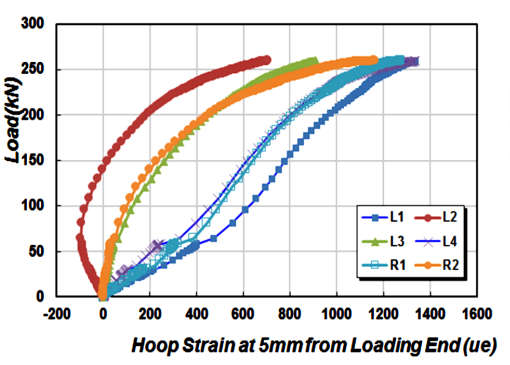

(a)

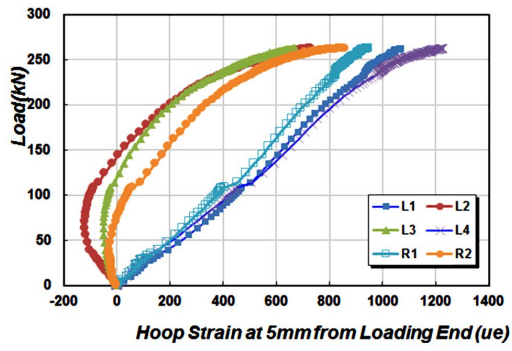

(b)

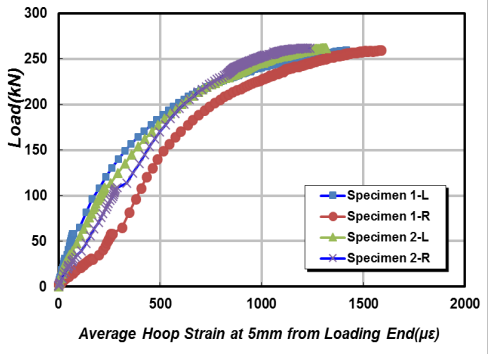

(c)

Figure 8. Load-hoop strain curves (at $5 \mathrm{~mm}$ from outer end of anchor head). (a) Load-hoop strain curves of specimen 1; (b) Load-hoop strain curves of specimen 2; (a) Load-average hoop strain curves

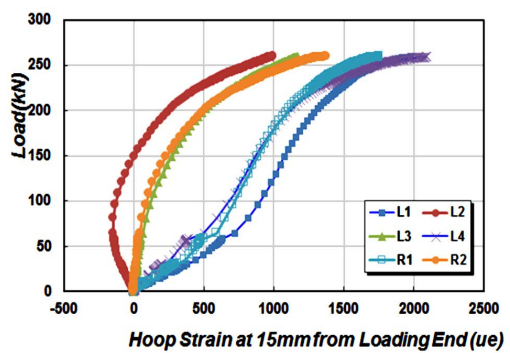

(a)

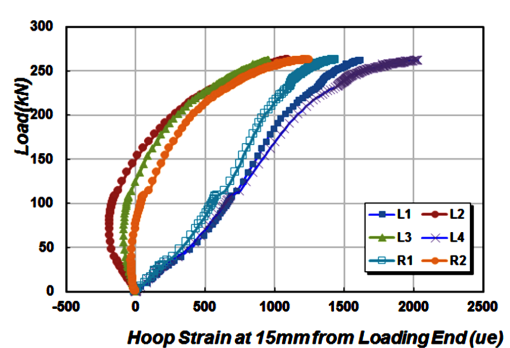

(b)

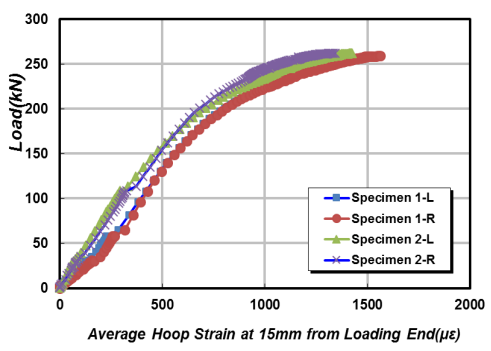

(c)

Figure 9. Load-hoop strain curves (at $15 \mathrm{~mm}$ from outer end of anchor head). (a) Load-hoop strain curves of specimen 1; (b) Load-hoop strain curves of specimen 2; (c) Load-average hoop strain curves.

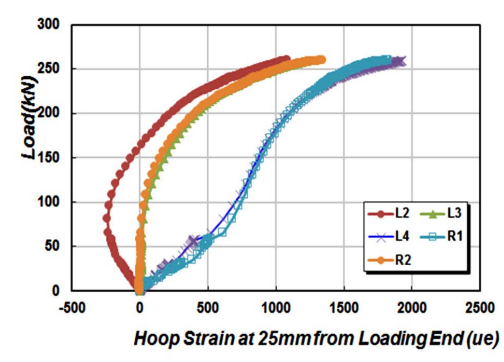

(a)

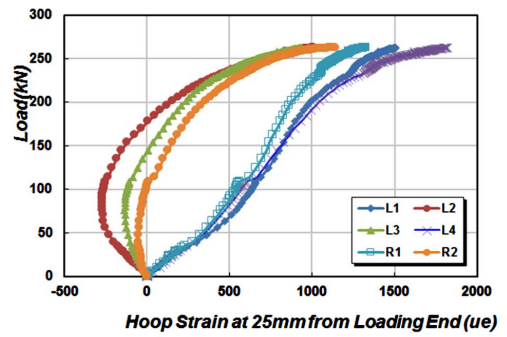

(b)

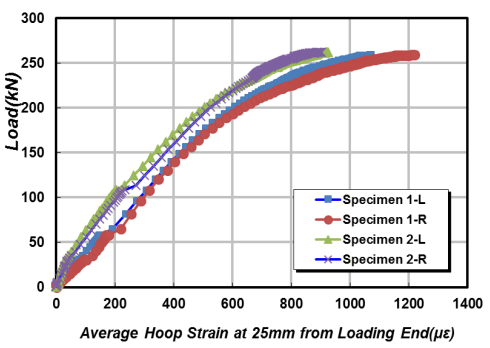

(c)

Figure 10. Load-hoop strain curves (at $25 \mathrm{~mm}$ from outer end of anchor head). (a) Load-hoop strain curves of specimen 1; (b) Load-hoop strain curves of specimen 2; (c) Load-average hoop strain curves.

Another objective of this study is to examine the possibility to estimate the prestressing force based upon the deformation characteristics of the anchor. Figure 11 shows an example of the analysis of the error using the average hoop strains at identical position, which exhibited the most stable pattern. For a given strain, the corresponding minimum and maximum loads, $P_{\min }$ and $P_{\max }$, are used to calculate the average load $P_{\text {ave }}=1 / 2\left(P_{\min }+\right.$ $\left.P_{\max }\right)$. Defining the error by $\Delta P / P_{\text {ave }}$ using the deviation $\Delta P=P_{\max }-P_{\min }$, the error can be computed with respect to the strain level.

Tables 1-3 arrange the error obtained using the test results. It can be observed that, on the whole, the error tends to decrease with larger strains with an error of about $10 \%$ between 800 to $1000 \mu \varepsilon$ known to be the principal strain range corresponding to the prestressing force. In Table 2, the responses at $15 \mathrm{~mm}$ showing the smallest error are seen to exhibit an error of $8 \%$ to $9 \%$ in the main observation range of the prestressing force. Such analysis of the error was done by comparing 4 anchor heads with identical conditions in 2 specimens. Test on a larger number of specimens is expected to result in larger error but the analysis enabled to verify the possibility to assess quantitatively the trends in the change of the prestressing force based upon the strain of the anchor head. 


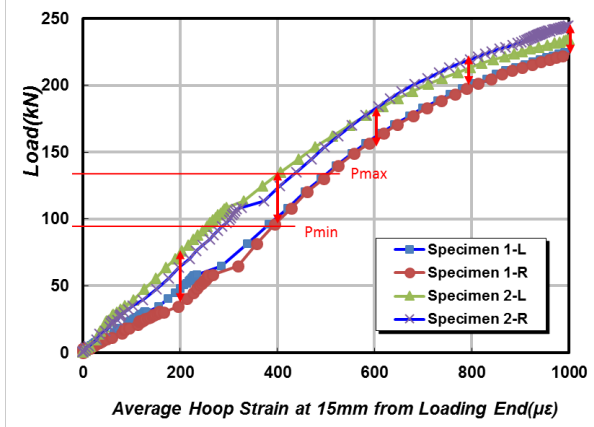

Figure 11. Evaluation of error using the load-average hoop strain curves.

Table 1. Error analysis of load-average hoop strain at $5 \mathrm{~mm}$ from outer end of anchor head.

\begin{tabular}{|c|c|c|c|c|c|}
\hline Strain & $P_{\min }$ & $P_{\max }$ & $\Delta P$ & $P_{\text {ave }}$ & Error (\%) \\
\hline $200 \mu \varepsilon$ & 34.8 & 97.0 & 62.2 & 65.9 & 94.4 \\
\hline $400 \mu \varepsilon$ & 108.36 & 164.0 & 55.7 & 136.2 & 40.9 \\
\hline $600 \mu \varepsilon$ & 170.75 & 195.8 & 25.1 & 183.3 & 13.7 \\
\hline $800 \mu \varepsilon$ & 205.0 & 228.8 & 23.8 & 216.9 & 11.0 \\
\hline $1000 \mu \varepsilon$ & 228.3 & 252.8 & 24.5 & 240.6 & 10.2 \\
\hline
\end{tabular}

Table 2. Error analysis of load-average hoop strain at $15 \mathrm{~mm}$ from outer end of anchor head.

\begin{tabular}{|c|c|c|c|c|c|}
\hline Strain & $P_{\min }$ & $P_{\max }$ & $\Delta P$ & $P_{\text {ave }}$ & Error (\%) \\
\hline $200 \mu \varepsilon$ & 34.8 & 76.0 & 41.2 & 55.4 & 74.4 \\
\hline $400 \mu \varepsilon$ & 96.0 & 135.5 & 39.3 & 115.7 & 34.0 \\
\hline $600 \mu \varepsilon$ & 156.8 & 184.3 & 27.5 & 170.6 & 16.1 \\
\hline $800 \mu \varepsilon$ & 201.8 & 219.3 & 17.5 & 210.6 & 8.3 \\
\hline $1000 \mu \varepsilon$ & 223.5 & 245.3 & 21.8 & 234.4 & 9.3 \\
\hline
\end{tabular}

Table 3. Error analysis of load-average hoop strain at $25 \mathrm{~mm}$ from outer end of anchor head.

\begin{tabular}{|c|c|c|c|c|c|}
\hline Strain & $P_{\min }$ & $P_{\max }$ & $\Delta P$ & $P_{\text {ave }}$ & Error (\%) \\
\hline $200 \mu \varepsilon$ & 64.8 & 101.3 & 36.5 & 83.1 & 43.9 \\
\hline $400 \mu \varepsilon$ & 140.0 & 162.0 & 22.0 & 151.0 & 14.6 \\
\hline $600 \mu \varepsilon$ & 193.5 & 219.3 & 25.8 & 206.4 & 12.5 \\
\hline $800 \mu \varepsilon$ & 226.0 & 255.3 & 29.3 & 240.7 & 12.2 \\
\hline $1000 \mu \varepsilon$ & 247.0 & - & - & - & - \\
\hline
\end{tabular}

\section{Conclusions}

This study examined experimentally the deformation characteristics of the mono tendon anchor head. Considering that the strains measurable in the anchor head are the axial and hoop strains, the deformation characteristics of the anchor head were analyzed by measuring these strains at various positions and according to the jacking force exerted on the prestressing strand. The test results revealed the occurrence of large variations in the axial strain and hoop strain with respect to the position. The large fluctuation of the axial strain could be explained by the relatively short length along which the load was transferred and the slight eccentricity of the loading. The hoop strain at identical distance from the outer end of the anchor head exhibited fluctuation induced by the effect of the coupled parts of the wedge and according to the measurement spot but the average value showed relatively small fluctuation.

In addition, the possibility to estimate the prestress force exerted on the tendon based upon the measured strains and the corresponding errors were also evaluated. The analysis revealed the feasibility to estimate the prestressing force using the average hoop strain and computed an error of 8 to $9 \%$ within the observation range of the prestress force. Accordingly, despite of a certain level of error, it was verified that the trends in the change of the prestressing force could be assessed quantitatively using the change in the strain measured in the anchor head. 


\section{Acknowledgements}

This research was supported by a grant from a Strategic Research Project "Development of Smart Prestressing and Monitoring Technologies for Prestressed Concrete Bridges” funded by the Korea Institute of Civil Engineering and Building Technology.

\section{References}

[1] Bastien, J., Marceau, D., Fafard, M. and Ganz, H.R. (2007) Use of FEA for Design of Posttensioning Anchor Head. Journal of Bridge Engineering, 12, 194-204. http://dx.doi.org/10.1061/(ASCE)1084-0702(2007)12:2(194)

[2] Noh, M.H., Seong, T.R. and Kim, J.K. (2012) Nonlinear Analysis of Anchor Head for High Strength Steel Strand. Journal of Computational Structural Engineering, COSEIK, 25, 163-173. (In Korean)

[3] Seo, J.W., Jeong, W., Cho, E.K. and Yoo, H. (2010) Parametric Analysis to Determine Optimum Geometries of PPWS Sockets in Cable-Suspension Bridges. Proceedings of Steel Structure, Korean Society of Steel Construction, Seoul, 3536. (In Korean)

[4] Park, J.H., Yang, H.J. and Cho, J.R. (2014) Numerical Analysis for the Deformation of a Mono Tendon Anchor Head. Journal of the Korean Society of Safety, 29, 25-30. http://dx.doi.org/10.14346/JKOSOS.2014.29.1.025

[5] Al-Mayah, A., Soudki, K. and Plumtree, A. (2001) Experimental and Analytical Investigation of a Stainless Steel Anchorage for CFRP Prestressing Tendons. PCI Journal, 46, 88-100. http://dx.doi.org/10.15554/pcij.03012001.88.100

[6] Al-Mayah, A., Soudki, K. and Plumtree, A. (2001) Mechanical Behavior of CFRP Rod Anchors under Tensile Loading. Journal of Composites for Construction, 5, 128-135. http://dx.doi.org/10.1061/(ASCE)1090-0268(2001)5:2(128)

[7] Al-Mayah, A., Soudki, K. and Plumtree, A. (2006) Development and Assessment of a New CFRP Rod-Anchor System for Prestressed Concrete. Applied Composite Materials, 13, 321-334. http://dx.doi.org/10.1007/s10443-006-9019-6

[8] Al-Mayah, A., Soudki, K. and Plumtree, A. (2006) FEM and Mathematical Models of the Interfacial Contact Behaviour of CFRP-Metal Couples. Composite Structures, 73, 33-40. http://dx.doi.org/10.1016/j.compstruct.2005.01.024

[9] Al-Mayah, A., Soudki, K. and Plumtree, A. (2006) Effect of Sleeve Material on Interfacial Contact Behavior of CFRPMetal Couples, Journal of Materials in Civil Engineering, 18, 825-830. http://dx.doi.org/10.1061/(ASCE)0899-1561(2006)18:6(825)

[10] Al-Mayah, A., Soudki, K. and Plumtree, A. (2007) Novel Anchor System for CFRP Rod: Finite-Element and Mathematical Models, Journal of Composites for Construction, 11, 469-476. http://dx.doi.org/10.1061/(ASCE)1090-0268(2007)11:5(469)

[11] Al-Mayah, A., Soudki, K. and Plumtree, A. (2008) Effect of Rod Profile and Strength on the Contact Behavior of CFRPMetal Couples. Composite Structures, 82, 19-27. http://dx.doi.org/10.1016/j.compstruct.2006.11.004

[12] Bennitz, A. (2008) Mechanical Anchorage of Prestressed CFRP Tendons: Theory and Test. Ph.D. Thesis, Luleå University of Technology, Luleå.

[13] Sayed-Ahmed, E.Y. and Shrive, N.G. (1998) A New Steel Anchorage System for Posttensioning Applications Using Carbon Fibre Reinforced Plastic Tendons. Canadian Journal of Civil Engineering, 25, 113-127. http://dx.doi.org/10.1139/197-054 
Scientific Research Publishing (SCIRP) is one of the largest Open Access journal publishers. It is currently publishing more than 200 open access, online, peer-reviewed journals covering a wide range of academic disciplines. SCIRP serves the worldwide academic communities and contributes to the progress and application of science with its publication.

Other selected journals from SCIRP are listed as below. Submit your manuscript to us via either submit@scirp.org or Online Submission Portal.
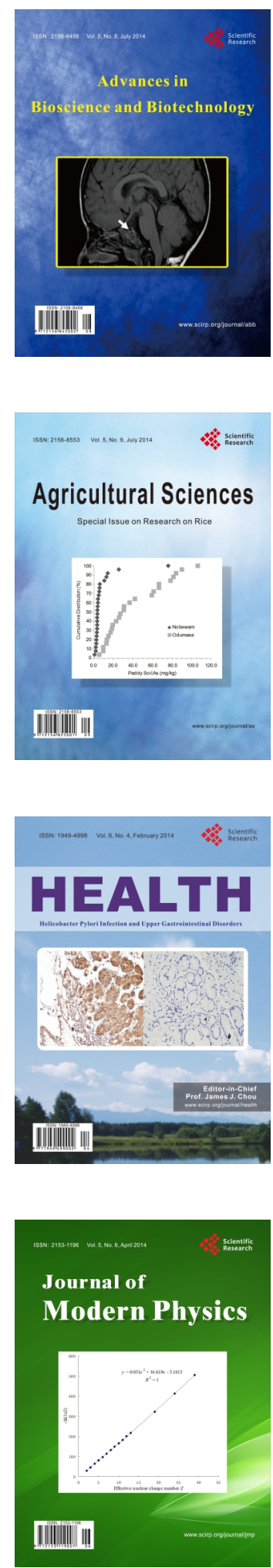
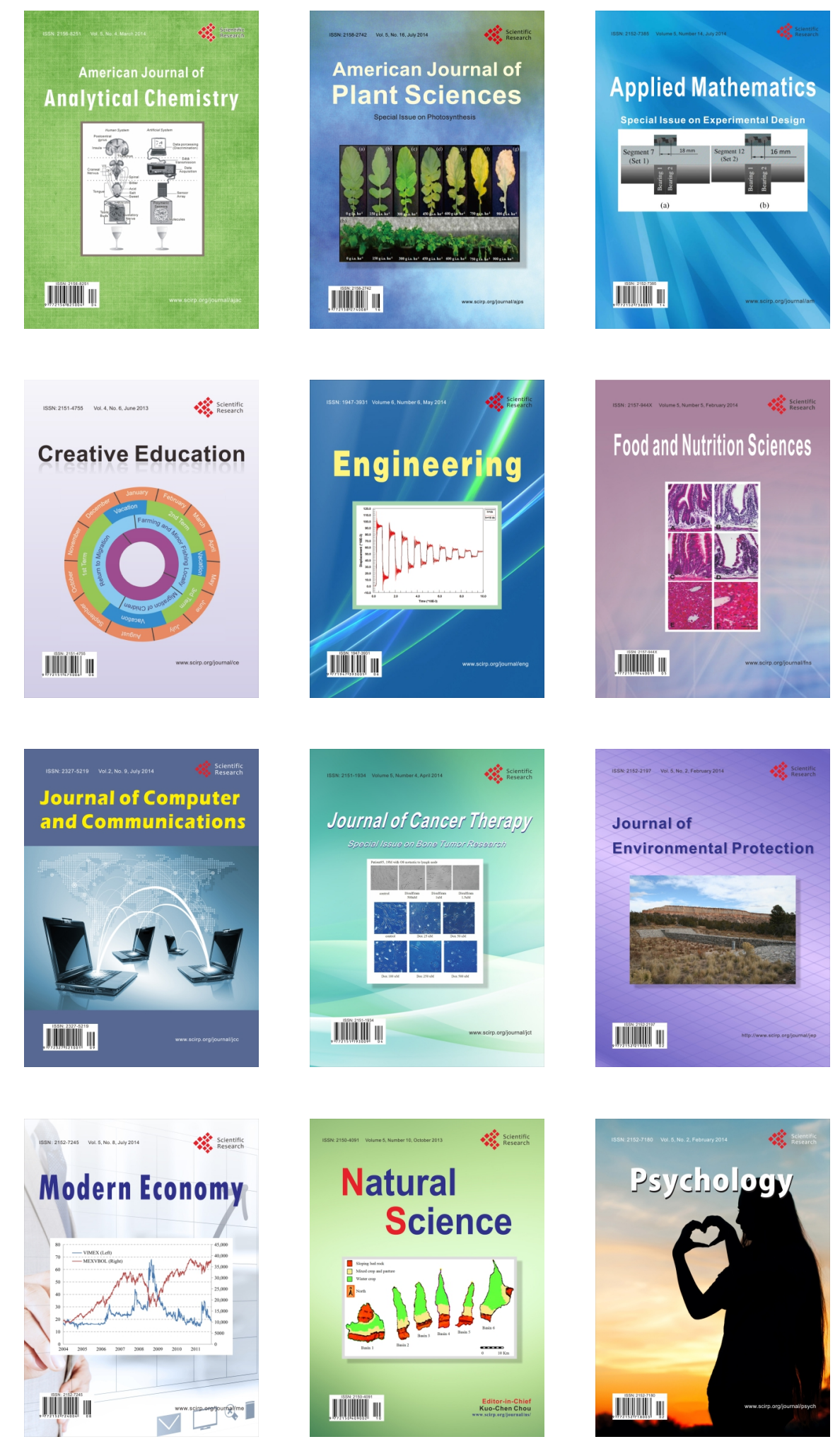